\title{
The Impact of the Geographical Distribution on Arabic Dialects' Translations from Arabic into English
}

Mostafa Mohamed Safwat Hassan Ahmed ${ }^{\left({ }^{*}\right)}$

\section{Abstract}

This study investigates the impact of the geographical distribution on dialect differences' translations from Arabic into English between Arab regions. It adopts the cultural translation theory in analyzing texts and the geographical distribution gauge's impact on the translation process. The theoretical background focuses on three major sections that constitute the core of this study; they are "translation", "the concept of dialects", and "Arabic dialects". First, it highlights the significance of translation, aspects of cultural translation as well as translation loss and untranslatability. Second, it highlights the concepts of dialects and social dialects. Third, it elaborates on the differences among the four groups of Arabic dialects with a distinctive linguistic affinity. They have been chosen for the study due to their geographical distribution. The problem of the study arises when translators use their cultural background while translating into English from different Arabic dialects and vice versa. This will lead to misunderstanding of context and therefore inaccurate translations. A test has been prepared to test out a sample of the words and expressions that have been collected. The methodology tackles this process. 30 participants from different Arab countries were asked to answer the test. The results of the test, as documented, and discussed,

${ }^{(*)}$ This paper is a part of M. A. thesis entitled: " The Impact of Arabic Dialect Differences on Arab Learners' Translations into English". Supervised by Prof.Bahaa-eddin M.Mazid- Faculty of Languages Sohag University \& . Dr.Hanan Abu-Altaher Ebeid - Faculty of Arts Sohag University. 
show that some words, phrases and sentences have more than one meaning in different countries. The conclusion of the study proves the validity of the research' main hypothesis; the level of understanding different Arabic dialects among Arabs depends on the person's own dialect and how much his/her dialect is affected by the various elements studied in the literature review. Especially important among them is the cultural background of the translator.

\section{Introduction}

Translation plays a pivotal role in promoting understanding among nations, as translators act as travelers among cultures, which helps in eliminating misunderstanding and feud. In addition, attitudes and options of recipients are highly affected by the ideas, values, opinions or perspectives that are brought into their culture via translated texts. Fortunately, the wide spreading of translation studies has become greater in the twenty first century. Such spreading has crossed the boundaries of Europe and reached Latin America, Africa, Asia, and Australia. Translation requires a combination of language ability, subject-specific knowledge, intuition, research skills, and judgment. A proper translation expresses the meaning behind the use of written words in one language in the written words of a second language.

One of the aspects that can have a direct impact on translation is dialect. A dialect is a variety of a language which has its own grammar and vocabulary and is spoken by a group of people in a particular area. Also, there are many elements and factors that affect the way people speak and pronounce words such as the geographical elements, their ethnic groups, religion, their activities ... etc. For example, people who speak the same language have different expressions according to their jobs as we can see with the specific expressions used by farmers, which 
are different from those used by sailors. The standard dialects of the language are used by governments, in the media, at schools and for international communication.

Arabic branches out into many dialects. Every region of the Arab World has its own specific dialect. There exist some semantic, syntactic, and morphological differences among them. They are the varieties which are spoken - and infrequently written - around the different parts of the Arab world.

\subsection{Objectives}

This study aims at identifying the differences between various dialects of the Arabic language according to the geographical distribution. It is an attempt to help translators find the best equivalence during the translation process.

\subsection{Questions}

This study attempts to answer the following questions:

1- What is the nature of the varied Arabic dialects which a translator can capture?

2- To what extent does the geographical distribution affect understanding between people in the Arab world?

\subsection{Significance of the Study}

The significance of the present study lies in the fact that it presents some varieties of the Arabic language that lead to ambiguity and confusion in the translation process. It can help bridge the gap of understanding among people all over the Arab world. For example, one single word or expression has one or more meanings in Egypt and totally different meanings in other Arab counties. Therefore, this study, hopefully, will help translators by providing relatively clearer meanings of such words or expressions across the Arabic dialects. 
Review of literature

\subsection{Theoretical Background}

This study is based by the cultural translation theory and the impact of the geographical distribution on Arab learners' translations into English. For many years the process of translation has not exceeded its narrow function of converting texts from one language to another, but this has widely changed into considering a wide range of elements such as geographical distribution. This study aims at conducting an analysis of the impact of the geographical distribution on Arabic dialects on translation through the Theory of Cultural Translation, in order to achieve the cultural equivalence between the source text and the targeted one. It is divided into three major sections: translation, dialects and Arabic dialects.

\subsection{Translation}

Translation came into being when a need for mutual understanding among different speakers of languages appeared. The differences between languages whose speakers contributed to the human culture made translation one of the main means of satisfying the needs for communication among people either individually or collectively. Newmark (1988) claims that translation is "a craft consisting in the attempt to replace a written message and/or statement in one language by the same message and/or statement in another language" (p.7). It is a process of delivering the message or idea to a receiver by replacing words of a language into those of another without changing the meaning or the main idea and overall spirit of the original text. It implies "the transferring of grammatical relationships, cultural conventions, ideologies, thoughts, and attitudes from L1 into L2. Thus, stressing that the purpose is not translation of single words nor 
translation of single construction, but the translation of coherent discourse" (Quine, 1978, p. 166).

The concept of "anyone can translate" led to misconceptions about who is able to translate. The needs of the translation process do not stop on being a bilingual person, as they require many skills. Holmes (1988) says: "The translator is, in this simplistic common-sense view, a kind of cross-linguistic transcriber or copyist, a slightly glorified typist” (p. 103). A translator is a person who enjoys high mentality and good logic. S/he is ever busy in contemplation and deep thinking. S/he is more than a typist. In the same token, a translator acts as a mediator between two or more different cultures. Nevertheless, some people view translation as an easy job that can be performed by anyone. Whyatt (2003) concludes that: "this kind of commonly shared expectations about the ease of translation comes from monolingual clients seeking translation services and from bilinguals themselves until they sit down with a text and try to perform the activity" (p. 82).

In the case of bilinguals, they cannot produce a professional translation as they may lack the skills needed for that sort of translation. It is a matter of fact that not anyone can assume the ability to translate professionally until they are involved in the process. Ellen Bialystok (1991) explains: "Yet, clearly, all bilinguals are able to translate at some level. To what extent the nature of their translation resembles that of trained interpreters is an open question- mainly because so little is known about the natural ability of bilingualism" (p. 143). Undoubtedly, those who assume full knowledge and awareness of both languages can be described as "exaggerated," as translation - as a mental activity requires well-grounded people in both the target and source languages. Whyatt, (2012) comments that: 
These common misconceptions about the human skill to translate texts/ utterances expressed in one language into another language most probably result from a simplified view of the translation process, which is perceived in the task as a process of linear transcoding of a string of words in a source language (SL) into a string of translation equivalents of these words in the target language (TL) text. (p. 24)

A translator must have competence, ability and good skills to translate professionally. It seems that the terminological confusion between ability, skill and competence is also present in the literature on translation, and although this problem will reoccur in further discussions, it is important to give it some attention before the major argument develops. Skills of translation are, for example, writing, reading and analyzing texts, good cultural awareness of both SL and TL, and attention to details. Firstly, as for writing, s/he must be professional in his or her own language: grammar, spelling, vocabulary and style. Also, s/he must be fully aware of the target language as well as the target culture.

The translation process also needs intensive preparation through study and practice. Study helps translation students master some skills to be able to produce professional translation. Practice, on the same footing, helps translation students apply and modify what they have learnt on the real situations taking into consideration the needs, nature, and circumstances of the surrounding society.

A translator should be perfectly aware at least one or two of legal, commercial, technical, literary, medical texts. S/he should enjoy a high degree of critical thinking, i.e., s/he has to subject every text to 
analysis and investigation with the aim of understanding the text, as well as the direct and indirect meaning of each word. Thirdly, professional translators need to have an excellent cultural awareness of both SL and TL. Any misunderstanding of the SL or TL will lead to inaccurate translation. Fourthly, translation has many difficulties, so translators have to pay a great attention to details to solve them.

Finally, the process of translation is not that simple one which any one can practice without special study and intensive practice. Universities and researchers have to pay a great attention to promoting the skills of translation and the way of developing them.

\subsection{Dialects}

Dialects can be defined as "sub-forms of languages which are, in general, mutually comprehensible" (Walkins \& Francis, 1998, p. 4). According to Crystal and Ivic (2015): "The word dialect comes from the Ancient Greek dialektos 'discourse, language, dialect,' which is derived from dialegesthai, "to discourse, talk"" (p. 1). The term "dialect" is used to describe a variety of a language; for example, Egyptian Arabic is considered a variety of Arabic. A variety of a language is also a characteristic of a particular group of the language speakers. The term is connected frequently to provincial discourse designs, yet, a dialect may likewise be characterized by various elements such as physical geography, social divisions and other elements.

Thus, it can be assumed that a speaker of a certain language can understand another speaker of the same language even if they belong to different areas, classes, or ethnic communities as is the case of the Arabs throughout the expansive Arab territories, the English speaking nations worldwide, as well as the French, Spanish, or Portuguese speaking peoples in the Americas or Africa. In common usage, a dialect 
is sometimes considered a substandard, low-status often rustic form of language, generally associated with the peasantry, the working class, or other groups lacking in prestige.

Physical geography, also, has its influence on dialect. Physical features like deserts, rivers, mountains, and the like hindered the spread of different words, short sentences, and expressions by hampering physical travel by dialect users. This influence plays a crucial role in the establishment of the varied dialects. Examples are the Connecticut River which serves as the natural boundary between Vermont and New Hampshire, Appalachian Mountains, the Rockies, and Mississippi River.

The differences between the dialect regions usually occur in three general areas: vocabulary, sound, and syntax. The following gives a brief example:

\begin{tabular}{|l|l|l|}
\hline Vocabulary & Southern & Midland \\
\hline Northern & snap beans & green beans \\
\hline Beans & spicket & spicket \\
\hline Faucet & fish worm & $\begin{array}{l}\text { fishing } \\
\text { worm }\end{array}$ \\
\hline angleworm & squirrel \\
ground & Squirrel \\
\hline $\begin{array}{l}\text { chipmunk } \\
\text { ground }\end{array}$ & pail & pail \\
\hline bucket pail & Poke & sack \\
\hline bag & & ant (aunt) \\
\hline Sound & ant (aunt) & fawg (fog) \\
\hline ahnt (aunt) & fawg (fog) & \\
\hline fahg (fog) & & \\
\hline
\end{tabular}

(Bushman, p. 56) 
Studying the above-mentioned influence of physical geography is what constitutes the discipline of dialect Geography. It is a science that is mainly studied by linguists rather than geographers, as they shed light on the elements of the language from the regional and geographical point of view. It is the study of dialect variations and their linguistic features by using maps and the distribution of populations, according to their social class or occupational group, who have their own grammar, pronunciation and vocabulary. It is also defined in thefreedictionary.com (2018) as: "the branch of linguistics that involves the study of regional variations of speech forms". This term is used to refer to a variety of language in a particular place for a particular time, which sheds light on two aspects that are time and space which form the main elements to study any literary work.

Each language has many regional dialects within it. "These dialects reflect the everyday experience of individuals living in different parts of the country and strongly shape their cultural identity" (Falck et al., 2010, p. 2). Therefore, linguists use dialect geography as a reference in analyzing literary works, reasons behind writing them and other elements as well.

\subsection{The Arabic Dialects}

Arabic is deeply rooted in the depths of history. It is the receptacle of the Islamic and Arabic legacy. Historically, it was the language of science and literature, in addition to its being the language of the Holy Quran. It is the means of communication amongst all Arabs, as it is the language of science, mass media, education, sports, courts, and literature throughout the Arab World. It is the key to the Islamic culture. It is the strongest link among all the Arabs. It acts as an integral core of Arab societies as it is spoken by more than 422 million persons. 
. It encompasses a lot of fairly mutually intelligible dialects, though one can find some differences among those dialects due to geographical and historical factors.

There are many different Arabic dialects in the Arab World which extends from the Arabian Gulf to the Atlantic Ocean, and even within one country, there are different dialects. All Arabic dialects are not standard and, therefore, they are not typically used in education, books, newspapers, street signs, or official documents. Ferguson (1959) claims that the Arabic language is one of the most popular examples of diglossia in that geographical distribution and cultural backgrounds play an important role in making Modern Standard Arabic (MSA) deeply different from its variants. Also, in addition to the geographical distribution, there are many various factors such as rurality and urbanity, religion, ethnicity, Bedouin or sedentary which deeply affect the way people speak, choose suitable words, behave and interact among each other. There are many Arabic dialects. Versteegh (1997) mentions that:

the Arabic dialects existed at a very early stage of the Islamic conquests. Although, most of the original languages of the occupied lands gradually died out, they had a phonological and a lexical influence on the spoken Arabic that has remained present in current Arabic dialects. (145)

Versteegh (1997) classifies Arabic into five groups of dialects with a distinctive linguistic affinity between the dialects of each group:

1. The dialects of the Arabian Peninsula

2. Mesopotamian dialects

3. Syro-Lebanese dialects

4. Egyptian dialects 
5. Maghreb dialects. (p. 145)

In addition to the previous classification of the Arabic dialects, Badawy (1973) classifies the levels of Arabic in modern Egypt alone into classical Arabic, modern standard Arabic (MSA), colloquial Arabic of the educated, colloquial Arabic of the enlightened, and colloquial Arabic of the uneducated. That classification can also be applied to other Arabic dialects across the Arab regions.

The Arabic language officially exists in 22 countries and it is taught in universities, schools and colleges. Meanwhile the term "Arabic language" is used to refer to the varieties of Arabic. Although MSA has both written and spoken forms, colloquial Arabic just has a spoken form, as it is just used for daily situations. The differences between MSA and Colloquial Arabic are not just linguistic but also semantic, lexical and syntactic.

There are negative effects in the case of Arabic language varieties because what is spoken is not written, which makes it difficult to obtain the adequate corpora to use. Since they are different from MSA, Arabic dialects do not have their own grammar rules controlled by an authoritative organization, but of course there is an idea of grammatical and ungrammatical structures. Also, despite the fact that they are spoken, it is possible to use Arabic letters to produce Arabic text by using the same spelling rules used in MSA. Therefore, the level of understanding different Arabic dialects among Arabs depends of the person's own dialect and how much his/ her culture is affected by the Arabic culture and literature from outside his/her country. Most Arab citizens, for example, do not have any problem in understanding the Egyptian dialect. Moreover, they sometimes speak it, thanks to Egyptian media and film making industry and their fame across the Arab world. On another level, 
the typical Arabic speaker can find some sort of difficulty in understanding the Moroccan dialect, especially in its spoken form. Therefore, from the scientific point of view, dialects can be considered separate languages in their own.

Due to geographical distributions as well as lots of historical events especially during the period of Ottoman rule and some other elements, most Arabic speakers began to use local Arabic dialects in their daily situations. Therefore, the vast majority of Arabic native speakers cannot produce sustained discourse spontaneously in MSA; in certain situations such as talk shows on TV and radio programmes and they often tend to use their local dialects and MSA interchangeably (Abu-Melhim, 1991; Bassiouney, 2009).

There are many Arabic dialects, as indicated, above, from which there are sub-dialects such as Algerian, Moroccan, Iraqi, Kuwaiti, Saudi, Jordanian, Syrian, etc. The Egyptian dialect is considered the most widespread dialect in the Arab world, because of the Egyptian media, and movie industry, and because of the leading Egyptian role in the region. Also, there was a direct impact of Egyptian teachers upon most of the Arab learners.

As for the Levantine, Bassiouney (2009) says that it includes some Aramic dialects which are spoken in Syria, Lebanon, Palestine, and Jordan. They have slight differences in the spoken form, while they have much in common in the written form. As for the Gulf dialect, although it is considered the closest dialect to MSA, there are major differences between it and MSA (Versteegh, 2001). The Iraqi dialect is sometimes considered one of the Gulf dialects. However, it has unique characteristics of its own in pronunciation, verb conjugation, prepositions (Mitchell, 1990). The Maghrebi dialect has been deeply 
influenced by the French and Berber languages. Also, Maghreb is a large region and has numerous variations that may subdivide further.

According to what has been discussed above, dialects are usually labeled according to major geographic areas. Within these broad classifications, the daily speech of urban, rural, and nomadic speakers can be distinctively different. The truth to say is that dialect changes from one town to the next in the Arab world. Formal Arabic is the official language of all Arab countries and is the only form of Arabic taught at schools at all stages.

\section{Methodology}

The following section introduces the methodology of the study. It covers the analytical tools, the strategies used for data analysis. The test exhibited and illustrated.

\subsection{Data collection}

In each interview the researcher was present and was keen to take notes and write down every minute detail related to the study. Interviews were one of the methods that were used to collect data. Another method of collecting data that was also used was the TV shows, namely, خواطر Jalassat Wenassah ولنسات وناسـه و (khawater) Hajar Ezzawyah

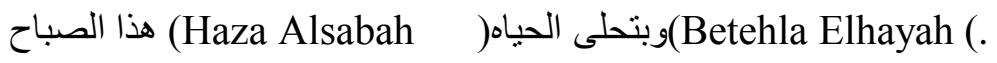

\section{Analysis}

\subsection{Word Level.}

Geographical distribution has a noticeable impact on participants' translations. The following tables present sample of words, short sentences and long sentences that will be analyzed after each table and that demonstrate the impact of geographical distribution's impact on participants' translations. 
Table 1.1

Sample of a Word and its Translations According to Geographical Distribution

\begin{tabular}{|c|c|c|}
\hline Word & Country & Translation \\
\hline \multirow[t]{9}{*}{ ناصح } & Egypt - مصر & Smart \\
\hline & السودان-Sudan & Smart \\
\hline & سوريا - Syria & Fat \\
\hline & لبنان- Lebanon & Fat \\
\hline & فلسطين- Palestine & Fat \\
\hline & الاردن- Jordan & Fat \\
\hline & KSA - السعوديه & Person gives an advice \\
\hline & الكويت- Kuwait & Preacher \\
\hline & ل الامار ات-UAE & Preacher \\
\hline
\end{tabular}

The /naaSiH/ word has totally three different meanings. Students from Arab Peninsula translate it as a "preacher" or a person who gives an advice, while Egyptian and Sudanese students translate it as a "smart person;" meanwhile students from the Levant region have translated it as "fat person".

Table 1.2

Sample of a Word and its Translations According to

Geographical Distribution

\begin{tabular}{|l|r|l|}
\hline Word & Country & \multicolumn{1}{|c|}{ Translation } \\
\hline ابشر الكويت- Kuwait & Ok \\
\hline & KSA & At your service - ok \\
\hline & Bahrain - السعودين- Ok \\
\hline
\end{tabular}


Bulletin of The Faculty of Arts, Vol. (57), No. (2) October 2020

\begin{tabular}{|c|c|c|}
\hline & الامار ات-UAE & Okay \\
\hline & Egypt - مصر & Good news \\
\hline & السودان-Sudan & $\begin{array}{l}\text { Happy news } \\
\text { (Something positive) }\end{array}$ \\
\hline & سوريا - Syria & Happy news \\
\hline & Iraq - العر اق & Good news \\
\hline & Tunisia - تونس & Happy news \\
\hline
\end{tabular}

The word /ab/ir/ has two different meanings and translations as the students from Saudi Arabia, Bahrain, and Kuwait translate it as "ok" or "at your service," while students from Egypt, Sudan, Syria, Iraq, and Tunisia translate it as "happy news" and "good news".

Table 1.3

Sample of a Word and its Translations According to

Geographical Distribution

\begin{tabular}{|c|c|c|}
\hline Word & Country & Translation \\
\hline \multirow[t]{8}{*}{ خشم } & Egypt - مصر & Mouth \\
\hline & السودان-Sudan & Mouth \\
\hline & KSA - السعوديه & Nose \\
\hline & Kuwait -الكويت & Nose \\
\hline & الامار ات-UAE & Nose \\
\hline & Syria- سوريا & Nose \\
\hline & لبنان-Lebanon & Nose \\
\hline & Palestine - فلسطين & Nose \\
\hline
\end{tabular}


The word /xa]m/ has two different meanings. The Egyptian and Sudanese students translate it as "mouth", while Levant and Arab Peninsula students translate it as "nose".

\subsection{Short Sentences Level.}

Table 2.1

Sample of a Sentence and its Translations According to Geographical Distribution

\begin{tabular}{|c|c|c|}
\hline Short sentence & Country & Translation \\
\hline \multirow[t]{9}{*}{ أريد أن آكل هريسه } & Egypt - مصر & I want basbousa. \\
\hline & Sudan-السودان & $\begin{array}{l}\text { I want to eat sweet } \\
\text { cake. }\end{array}$ \\
\hline & Syria- سوريا & $\begin{array}{l}\text { I want to eat basbousa } \\
\text { "Harisa". }\end{array}$ \\
\hline & KSA - السعوديه & $\begin{array}{l}\text { I want to eat mashed } \\
\text { potato }\end{array}$ \\
\hline & Kuwait - الكويت & $\begin{array}{l}\text { I want to eat mashed } \\
\text { potato }\end{array}$ \\
\hline & تونس- Tunisia & I want hot spices \\
\hline & المغرب- Morocco & I want hot sauce \\
\hline & Algeria - الجز ائر & I want to eat hot spices \\
\hline & ليبيا- Libya & I want to eat hot spices \\
\hline
\end{tabular}

The above short sentence /uri:du an akul həri:səh/ has three different meanings. The Egyptian Sudanese and Syrian students have translated it as "I want to eat basbousa" or "harissa" which is a "sweet cake". The students of the Arab Peninsula have translated it as "I want to eat mashed potato". Meanwhile, students of Maghreb countries have translated it as "I want to eat hot spices", or "I want hot sauce". 
Table 2.2

Sample of a Short sentence/Sentence and its Translations

According to Geographical Distribution

\begin{tabular}{|c|c|c|}
\hline $\begin{array}{l}\text { Short } \\
\text { sentence }\end{array}$ & Country & Translation \\
\hline \multirow[t]{7}{*}{ اصلح الدو لاب } & Egypt - مصر & Fix the closet \\
\hline & Sudan-السو دان & Fix the closet \\
\hline & Syria- سوريا & Fix the tier \\
\hline & لبنان-Lebanon & Fix the tier \\
\hline & العر اق-Iraq & Fix the tier \\
\hline & الاردن- Jordan & Fix the tier \\
\hline & فلسطين- Palestine & Fix the tier \\
\hline
\end{tabular}

The above short sentence /asleh al dwlab/ has two different meanings. The Egyptian and Sudanese students translate it as "Fix the closet", while Levant's students translate it as "Fix the tier".

\section{Discussion}

In table 1.1 the word "ناصح" - /naaSiH/ in the Gulf region means someone who gives advice or a preacher. This meaning comes from the verb "نصحح". In Egypt it means "smart" which partly agrees with the one who is aware about what is right or wrong. However, it means fat in Levantine area. In table 1.2 the word "ابشر"- /abfir/ has two different meanings and translations as the students from Saudi Arabia, Bahrain, and Kuwait translate it as "ok" or "at your service", while students from Egypt, the Sudan, Syria, Iraq, and Tunisia translate it as "happy news" and "good news". In table 1.3 the word "خشم" - /xa]m/ means "mouth" only in Egypt and Sudan, while it means "nose" in the Gulf, Levantine and the Maghreb countries. 
As seen from these examples, collections of regionally close countries tend to have similar meanings of words. This is a result of geo/historical factors as in the case of Egypt and Sudan which are closely related and used to be one country. The same applies to the Gulf countries who originally descend from the same tribal roots. Similarly, the neighboring Levantine countries also share a long common history and used to be one nation. Finally, the Maghreb countries which have the same Arabic, Berber, and Amazigh cultural backgrounds and the French colonial experience.

اريد " On the short sentences level, in table 2.1 the short sentence ان اكل هريسه /luri:du an akul həri:səh/ is an example of the geographical distribution. It means "I want to eat hot spices" or "I want hot sauce" in the Maghreb countries. In Egypt, Yemen and the Sudan, it means "I want to eat sweet cake" or "I want Basbousa", but it means "I want to eat mashed potato" or "I want to eat some grits" in the Gulf. Despite the fact that the three meanings of the above examples can be related back to the origin of the word in MSA, the geographical distribution factor determines which of the three meanings each region adopted. In table 2.3 the short sentence أاريد أن أصلح الدولاب" /asleh al dwlab/ has two different meanings. Therefore, the Egyptian and Sudanese students translate it as "Fix the closet", while Levant's students translate it as "Fix the tyre".

In conclusion, as documented in the review of literature and proved through the analysis and discussion of the test in this thesis, a translator or an interpreter's task is to figure out how best to substitute words from one language for words in another language, taking into account the context's implied meanings inclusing the culture and the history of both languages, and the geographical distribution's impact on 
the translation process all while working his/her way through translation problems such as ambiguity, translation loss and untranslatability.

This study investigates the impact of Arabic dialect differences on Arab learners' translations through the cultural translation theory. The study works through three main dimensions which are translation, dialects, and Arabic dialects. It investigates how translation is affected by dialect differences. The problem arises when translators are affected by their cultural background while translating from different Arabic dialects into English and vice versa. This will lead to misunderstanding and therefore inaccurate translation.

\section{Conclusion}

This study investigates the impact of the geographical distribution on Arab learners' translations through the cultural translation theory. The study works through three main dimensions which are translation, dialects, and Arabic dialects. It investigates how translation is affected by geographical distribution. The problem arises when translators are affected by the element of geographical distribution while translating from different Arabic dialects into English and vice versa. This will lead to misunderstanding and therefore inaccurate translation.

\section{$\underline{\text { References }}$}

Abu-Melhim, A. (1991). Codeswitching and linguistic accommodation in Arabic. Perspectives on Arabic Linguistics. III, 231-250. Papers from the Third Annual Symposium on Arabic Linguistics, John Benjamins Publishing Company. Retrieved on Oct. 2018 from https//doi.org/10.1075/cilt.80.15abu

Bialystok, E. (1991). Language processing in bilingual children. Cambridge University Press. 
Bushman, J. (1989). Exploring the geographical dialects of English. Language Arts Journal of Michigan, 5(2), 54-61.

Falck, O. (2010). Dialects, cultural identity, and economic exchange. IZA $D P .4743 .$, Institute for the Study of Labor, Germany.

Ferguson, C. A. (1959). DIGLOSSIA. Word-Journal of the International Linguistic Association, 15(2), 325-340.

Holmes, J. (1988). Translated Papers on Library Translation and Translation Studies. Rodopi.

Mitchell, T. (1990). Pronouncing Arabic. Clarendon Press.

Newmark, P. (1988). A Textbook of translation. Prentice Hall.

Newmark, P. (2001). Approaches to translation. Pergamon Press Oxford.

Pavle, I. and Crystal, D., (2015), available at http://www.britannica.com/topic/dialect

Quine, W. V. (1978). Afterthoughts on metaphor: A postscript on metaphor. Critica Inquiry, 5, 161-166.

Versteegh, K. (1997). The Arabic language. Edinburgh. Edinburgh University Press Bassiouney, R. (2009). Arabic sociolinguistics. Edinburgh University Press.

Wakelin, M. (1998). Discovering English dialects. Oxford, Shire Publications.

Whyatt, B. (2003). Reading for translation: Investigating the process of foreign language text comprehension from an information processing perspective. Studia Anglica Posnaniensia, 39, 133 - 147. Mickiewicz University. Poznan.

Whyatt, B. (2012). Translation as a human skill. Mickiewicz University. Poznan. 